\title{
Trabalho social cubano e tendências teóricas atuais
}

\author{
Cuban social work and current theoretical trends \\ JOSÉ FERNANDO SIQUEIRA DA SILVA ๑ \\ Universidade Estadual Paulista (UNESP), São Paulo, São Paulo, Brasil.
}

RESUMO - Este artigo tem por objetivo abordar as tendências teóricas do trabalho social cubano a partir do início da transição socialista na llha (janeiro de 1959). Para tanto, recupera aspectos da história mais recente deste país e situa a importância do movimento 26 de julho (M-26-7) que lutou contra a ditadura de Fulgencio Batista que culminou como a transição socialista e a reestruturação do trabalho social em Cuba. Destaca, ainda, as principais inspirações teórico-políticas que têm orientado o sentido do trabalho social cubano nos últimos 25 anos, suas diversas tendências, seus elementos constituintes, suas teses centrais. Analisa, por fim, com base nesse estudo, os limites e as potencialidades para consolidar uma formação universitária profissional crítica na Ilha, fiel à tradição socialista nela construída e caudatária de suas experiências militantes e progressistas.

Palavras-chave: Tendência Teóricas. Trabalho Social. Transição Socialista.

ABSTRACT - This paper considers the theoretical tendencies of Cuban Social Work from the beginning of the socialist transition in the island (January 1959). For this purpose, revisits aspects of recent Cuban history, locates the importance of the 26 of July movement (M-26-7) which fought Fulgencio Batista's dictatorship and culminated with socialist transition and the reorganization of Social Work in Cuba. The paper also emphasizes the most important theoretical inspirations which oriented Cuban social work in the last 25 years, its various tendencies, its constitutive elements and central theses. Finally, based on its findings, the paper analyses the limits and potentialities for the consolidation of a critical professional social work university education in the island, aligned to its socialist tradition and in the light of its progressive militant experiences.

Keywords: Social Work Theoretical tendencies. Social Work. Cuban Socialist transition. 


\section{Observações introdutórias ${ }^{1}$}

A

vitória dos "barbudos" caribenhos em janeiro de 1959 deixou a América e o mundo perplexos. O triunfo do "Movimiento 26 de Julio", liderado por Fidel Castro Ruz, desencadeou a experiência de transição socialista mais radical em solo americano. Inicialmente caracterizado como uma revolta popular-armada que depôs o ditador Fulgencio Batista - orgânico ao império estadunidense -, o movimento radicalizou-se continuadamente entre janeiro de 1959 e outubro de 1962. A “Batalla de Girón", em 1961, vencida pelos cubanos, e a crise dos mísseis em outubro de 1962, marcaram o rompimento que já estava em curso entre os EUA e Cuba.

O desfecho, já conhecido, foi o alinhamento da Ilha com o "Pacto de Varsóvia" liderado pela ex-União Soviética e a radicalização da Revolução Cubana na direção da transição socialista em tempos de Guerra Fria. O embargo econômico persiste há mais de meio século, mesmo após a morte de Fidel Castro em novembro de 2016 e a transição política na Ilha em abril de 2018. Os ianques continuam buscando motivos para enquadrar Cuba ao que chamam de "eixo do mal", quando o que de fato desejam é seu alinhamento incondicional (BORON, 2014).

Sem perquirir a densidade deste processo, o que demandaria um artigo de muito maior fôlego, é necessário destacar sumariamente que a América, como um todo, nunca mais foi e nem será a mesma após o feito cubano. A influência da Revolução Cubana foi decisiva durante a década de 1960, teve presença significativa nos anos 1970-1980 e se manteve viva, por outros caminhos, após a queda da URSS e o terrível período especial que devastou a llha nos anos 1990.

O seu legado impactou as esquerdas e as direitas, estimulou golpes militares financiados pelos EUA por todo cone sul da América nas décadas de 1960 e 1970, bem como alimentou rebeldias e projetos que pulsam até hoje por toda América Latina. O que parece certo é que tanto a desqualificação como a romantização desta experiência agem contra a razão crítica empenhada em reconstruir a dinâmica do real.

O "concreto-pensado" marxiano (MARX, 1989, p. 210) exige o debruçar sobre condições históricas objetivas, materialmente dadas, bem como estimula a análise radical nada afeita a messianismos e a logicismos. Nisso, as bases materiais não para interpretar e contemplar o mundo, mas transformá-lo (MARX, 2007 , p. 535). A realidade cubana continua desafiadora, seja como um importante legado das esquerdas latino-americanas, seja como parte constituinte do desafio atual e concreto para os que miram "para além do capital".

No âmbito do Serviço Social na América Latina o processo cubano inspirou os setores mais avançados do diverso Movimento de Reconceituação latino-americano (NETTO, 1991). A Revolução Cubana e seu legado, com seus acertos e erros, é parte ativa do acervo latino-americano libertário, particularmente aquele comprometido com níveis crescentes de emancipação social.

\section{A encruzilhada cubana}

A América Latina sempre ocupou papel estratégico na gênese, no desenvolvimento e na consolidação da ordem burguesa mundial. Foi assim em todo continente centro-sul americano, na sua fração espanhola e ou portuguesa, com suas devidas particularidades, desde quando o pacto colonial impôs às colônias a transferência de suas riquezas que alimentou a "assim chamada acumulação primitiva" (MARX, 1984, p. 261). Esta sangria subsidiou decisivamente a revolução industrial inglesa que, gradualmente, generalizou-se e transferiu o foco da acumulação à produção industrial, tempo em que Karl Marx destrinchou o capital como relação social que expropria, acumula, centraliza e privatiza a riqueza socialmente produzida.

A fase industrial da acumulação, cujo ápice se deu no século XIX, não eliminou o comércio, mas o reorganizou em um complexo e dinâmico circuito reproduzido mundialmente (produção, circulação e comercialização/venda), processo este que se reinicia exponencialmente em diferentes segmentos da economia com o estímulo do crédito oferecido como dinheiro adiantado por bancos e utilizado pelas unidades produtivas como capital monetário investido na produção. ${ }^{2} \mathrm{~A}$ América Latina já desempenhava um 
papel mundial na divisão social do trabalho: fornecer matérias primas e produtos agrícolas. Cuba não fugia da regra, ainda que expressasse sua particularidade nesta complexidade: a grande propriedade açucareira, sustentada no trabalho escravo (abolido em 1887), inicialmente sob o comando espanhol que se transformou na grande propriedade capitalista açucareira comandada pelo capital norte-americano a partir de 1902.

Las guerras de independencia de Cuba (1868-1878 y 1895-1898), el fin de la trata o comercio de esclavos y la abolición de la esclavitud en 1887 en la Isla, allanaron el camino a la transformación del sistema de plantación esclavista en un sistema de latifundio y gran empresa capitalista en la agricultura. Estas transformaciones que ocurren en la sociedad cubana a finales del siglo XIX, coinciden con la entrada del capital norteamericano a la Isla y el inicio de su creciente dependencia del mercado norteamericano, que se acentúa por el debilitamiento del poder colonial español como consecuencia de la guerra de independencia de Cuba - su colonia más rica -; la entrada de Estados Unidos en la guerra, que da lugar a la Guerra HispanoCubano-Norteamericana; la derrota del ejército colonial español y la intervención norteamericana en Cuba que se extendió hasta 1902 (MASTRAPA e QUINTANA, 2016, p. 42).

A era monopólica do capital (final do século XIX e século XX), inaugurou um novo momento. Lenin (2008, p. 89) destaca que esta etapa da acumulação é marcada pelo imperialismo, ou seja, a fase superior do capitalismo em que os monopólios se organizam na forma de trustes e cartéis comprometidos com a dominação de mercados. O capital financeiro, então, nasce da fusão entre o capital bancário e industrial e os estados nacionais e os fundos públicos são capturados organicamente como parte constituinte do processo de acumulação. ${ }^{3}$

O comércio e a indústria são mantidos e adensados por uma engrenagem financeira que tenderia não apenas a potenciar a produção e os mercados por meio do crédito, mas também adensaria a influência do capital fictício, especulativo, crescentemente a partir da segunda metade do século XX. As colônias, também latino-americanas, continuariam úteis para fornecer matéria prima necessária às economias imperialistas e receber capitais excedentes investidos conforme os interesses metropolitanos.

A posse de colônias é a única coisa que garante de maneira completa o êxito do monopólio contra todas as contingências da luta com os adversários, mesmo quando esta procura defender-se mediante uma lei que implante o monopólio de Estado. Quanto mais desenvolvido está o capitalismo, quanto mais sensível se torna a insuficiência de matérias primas em todo o mundo, tanto mais encarniçada é a luta pela aquisição de colônias. [...] Os interesses da exportação de capitais levam do mesmo modo à conquista de colônias, pois o mercado colonial é mais fácil (e por vezes só nele é possível), utilizando meios monopolistas, suprimir o concorrente, garantir encomendas, consolidar as relações necessárias, etc. (LENIN, 2008, p. 83 e 85)

O moderno colonialismo sustenta sua dominação em um modelo dependente-associado (FERNANDES, 2009 , p. 60). Em outras palavras, as economias dependentes (MARINI, 2008) são reorganizadas sob o comando da modernização conservadora que atualiza a exportação de produtos primários, prioriza os interesses exteriores e o mercado externo, bem como associa os anseios das burguesias nacionais com demandas criadas fora das fronteiras de seus países. ${ }^{4}$ Ruy Mauro Marini assim caracteriza a dependência:

[...] relación de subordinación entre naciones formalmente independientes, en cuyo marco las relaciones de producción de las naciones subordinadas son modificadas o recreadas para asegurar la reproducción ampliada de la dependencia (MARINI, 2008, p. 111).

Na mesma perspectiva, mas como outros argumentos analíticos, destaca Florestan Fernandes: 
A dependência, por sua vez, não é mera "condição" ou "acidente". A articulação estrutural de dinamismos econômicos externos e internos requer uma permanente vantagem estratégica do polo econômico hegemônico, aceita como compensatória, útil e criadora pelo outro polo. ${ }^{5}[. .$.$] os parceiros internos [...] pensam que usando tal$ método tornam o processo mais "lucrativo", "rápido" e "seguro". Privilegiam, assim, as vantagens relativas do polo dinâmico mais forte porque "jogam nelas" e pretendem realizar-se através dela (FERNANDES, 2009, p. 60).

Ora, o que significou a Revolução Cubana? Uma ruptura com essa tradição dependente cuja base colonial esteve sob o comando espanhol, que entrou em decadência na segunda metade do século XIX. A constituição da República de Cuba (1902) expressou, ao mesmo tempo, a superação do domínio colonial espanhol e a ascensão do domínio imperialista norte-americano, que reinou até janeiro de 1959.

As bases agroexportadoras foram rigorosamente mantidas pelos EUA, especificamente a economia açucareira, sem qualquer consequência construtiva para os cubanos e para o país. A ação guerrilheira liderada por Fidel Castro, responsável pela deposição de Batista, continha demandas genuinamente libertárias que reavivaram os ideais anticoloniais objetivados na luta travada pelo jornalista, filósofo e poeta revolucionário cubano José Martí (fundador do Partido Revolucionário Cubano - PRC, em 1892).

O “Movimiento 26 de Julio" encarnou esta tradição, atualizou suas demandas e o inimigo, enfrentou o moderno imperialismo e seu modelo: a dependência. Mais do que isso, soube capturar os anseios libertários que moviam a sociedade cubana no final dos anos 1950, bem como apresentou um projeto alternativo ao que vigorava até então sob o comando direto dos Estados Unidos. A ascensão de Fidel e a vitória guerrilheira que contou com forte base popular, foi produto deste complexo contexto que já era marcado pela conjuntura da Guerra Fria.

A fase revolucionária cubana não se revelou, todavia, como um "mar de rosas". Ela foi marcada por contradições, avanços e retrocessos, bem como é impensável sem a influência soviética. Isso, evidentemente, não invalida o movimento, suas importantes particularidades, mas revela limites inevitáveis estabelecidos por um mundo capitalista, por condições peculiares estabelecidas pela Guerra Fria, bem como por erros cometidos ao longo deste processo.

O modelo revolucionário cubano, com todas suas contradições, construiu um projeto de transição socialista entre 1959 e 1989 nas condições objetivamente dadas. Durante esses 30 anos de presença soviética na Ilha se fez presente, adensando-se na década de 1970 e paulatinamente desacelerando-se a partir da segunda metade dos anos 1980.

Cuba, até então, exercia um papel específico no Conselho de Assistência Econômica Mútua (COMECON), o bloco econômico liderado pela extinta URSS: o fornecimento de açúcar obtendo em troca divisas que foram utilizadas pelo governo revolucionário para ampliar os níveis de vida do povo, desde a eliminação da pobreza absoluta, até a conquista de necessidades humanas essenciais (sobretudo, saúde e educação universais). A ausência de alguns produtos não essenciais até a primeira metade dos anos 1980 era suprida por condições de vida superiores ao padrão latino-americano, com índices comparados a nações de primeiro mundo. A contradição, todavia, se mantinha: a centralidade da produção açucareira na economia cubana (que chegou a contar com um ministério específico do açúcar) e o pequeno desenvolvimento em outras áreas essenciais ao país (em que pese o importante uso dos recursos obtidos por meio do açúcar em benefício do povo cubano) ${ }^{6}$.

O fim da URSS e do bloco por ela liderado teve um impacto fulminante e devastador na Ilha. A crise dos anos 1990 destruiu a economia e a sociedade cubana. A geração que apoiou a revolução foi exposta a situações extremas - por ela desconhecida - e uma nova geração se formou a partir desse legado. Essa devastação vivida durante o "período especial” recriou o pauperismo absoluto em Cuba, afetou substancialmente a orientação universalista do sistema cubano, alterou profundamente as relações de trabalho, priorizou necessidades emergenciais e exigiu uma reorganização econômica que pudesse enfrentar o desastroso cenário. Nas palavras de Fidel Castro: 


\begin{abstract}
O país sofreu um golpe devastador quando, de um dia para o outro, aquela potência desmoronou e nos deixou sozinhos, e perdemos todos os mercados do açúcar e deixamos de receber mantimentos, combustível e até a madeira para fazer os caixões para os nossos mortos. Ficamos sem combustível de um dia para o outro, sem matériasprimas, sem alimentos, sem higiene, sem nada. E todos pensavam: "Isso tudo vai desmoronar". E alguns idiotas continuam pensando que vamos cair, e que se não for agora vai ser depois. E, quanto mais ilusões eles tenham e mais esperarem por isso, mais devemos pensar em nós mesmos, e mais devemos tirar nossas próprias conclusões, para que jamais a derrota possa se abater sobre esse glorioso povo (RAMONET, 2006, p. 332).
\end{abstract}

Foi neste contexto que o turismo apareceu como um "remédio" com duros efeitos colaterais, embora tenha permitido estabelecer um patamar inicial de recuperação da economia cubana. Ao mesmo tempo, a produção açucareira deixou de ser central na economia do país, liberando terras para a produção de alimentos para o consumo interno, propriedades estas coordenadas por pequenos produtores privados. Ademais, recursos oriundos do exterior, não sem a gestão estatal, aqueceram a economia do país, ao mesmo tempo em que a área biotecnológica se desenvolveu aproveitando os altos índices educacionais existentes e o acúmulo na área da saúde. Dos anos 2000 em diante a economia deu sinais de lenta recuperação - mesmo com o acirrado embargo econômico mantido pelos EUA -, estabilização que se confirmou nos últimos anos. Sobre a presença do turismo na Ilha destaca o próprio Fidel (RAMONET, 2006, p. 440):

[...] a ideia de empresas mistas já tínhamos desde antes, ou melhor, o desenvolvimento do turismo. [...] a ideia de algumas empresas mistas também; mas então, fundamentalmente, o que fizemos foram medidas econômicas moderadas, não dá para se lançar em uma aventura dessas. Fizemos empresas mistas, estudamos as características, onde era conveniente, onde não era conveniente. Suportamos o incômodo das lojas em divisas. Compreendíamos os inconvenientes do turismo.

Sendo assim, não há dúvidas: Cuba tem passado por processos que retomam características afeitas às sociedades regidas pelo mercado, sobretudo a partir do final dos anos 1990 com a abertura ao turismo. Isso tem ocorrido, todavia, não por rendição do estado e da sociedade cubana à ordem burguesa em curso e a seu eterno receituário à América Latina: a dependência gestada sob o comando do imperialismo. O que está em questão é a sobrevivência do país e de seu povo, nisto a adoção de medidas inevitáveis em um mundo cujo comando é do capital. Diante disto, não existem ações isoladas e quixotescas.

Por outro lado, não nos parece correto afirmar que Cuba abandonou o projeto revolucionário gestado desde 1959, ainda que seja absolutamente necessário reconhecer que as medidas tomadas a partir do final dos anos 1990 não façam parte, em tese, de um projeto de inspiração socialista, como sociedades pós-capitalistas em movimento de ruptura com o capitalismo e com o capital (diga-se de passagem, pauta de processos revolucionários que não se limitam às fronteiras nacionais). Em outras palavras, a ênfase do "trabalho por conta própria", o estímulo a pequenos negócios e ao empreendedorismo (sobretudo, mas não somente, nos recentes pequenos restaurantes que alimentam o turismo denominados "paladares"), a ênfase na produtividade do trabalho, a gestão compartilhada de grandes negócios hoteleiros (em curso desde o início dos anos 2000), a entrega de terras a pequenos proprietários, entre outras iniciativas, estão sendo intensificadas na Ilha não por uma crença cega do governo cubano ou de parte dos cubanos na propriedade privada dos meios de produção, mas como a única forma para manter condições razoáveis de vida no cenário atual.

Há de se observar, ainda, como são gerenciados os recursos advindos de tais negócios, a quem são destinados, a defesa da saúde e da educação públicas em todos os níveis, a retomada do cooperativismo, a criação de programas mais focalizados, embora sem o desejo de substituir a orientação universalista, medidas adotadas não para subsidiar a sociedade burguesa em curso, suas desigualdades sociais, colocando a dispor do capital os fundos públicos, mas procedimentos postos em prática, nas condições atuais, para a defesa de certo legado propiciado pelo projeto de inspiração socialista objetivado depois de $1959 .^{7}$ 
Certamente existem muitas controvérsias sobre este contexto: haveria como resistir ingerindo um "remédio" que consome o projeto socialista por dentro? Como lidar com essa contradição sem projetos mundiais consistentes? A resposta não é simples, mas uma perspectiva progressista e anticapitalista não sobrevive sem três elementos dinâmicos que não podem ser pensados separadamente: a) o adensamento de um projeto mundial de esquerda ao menos de inspiração marxista (o que supõe o debate de tendências progressistas não idênticas); b) a resistência local/regional afinada com a direção mundial (pautando demandas particulares destes espaços); c) o colapso objetivo do capitalismo e do capital.

A ausência deste processo por inteiro, sua fragmentação, enfraquece qualquer tentativa mais localizada de resistência à sociedade burguesa em curso, ainda que não invalide - e isso não deve ser subestimado - tais experiências como parte de um legado anticapitalista progressista. É exatamente neste espaço contraditório que se inscrevem as recentes "aproximações" entre os Estados Unidos e Cuba (desaceleradas no governo Donald Trump). São essas as condições objetivas por onde se desenvolvem as atuais tendências teórico-políticas no país, também no Trabalho Social, incorporando e descartando tradições teóricas ou seus fragmentos - no ímpeto de gerenciar questões cotidianamente dadas. Há aqui, certamente, um ecletismo teórico-metodológico nada desprezível, ainda que a finalidade seja a de defender conquistas históricas.

\section{O Trabalho Social cubano: tendências teóricas atuais}

Como já destacado por Silva e Carmo (2015, p. 147), os termos "Trabajo Social" e "Trabajador Social" em Cuba possuem, hoje, conotações bastante abrangentes. Eles orbitam entre o entendimento profissional generalizado na divisão social do trabalho capitalista (com as adequações necessárias de um trabalho que se reorganizou a partir das condições da economia planejada socialista), até práticas de perfil militante comprometidas com os ideais da revolução iniciada em janeiro de 1959. Ao mesmo tempo, a palavra "tendências teóricas" remete a orientações teórico-práticas gerais que sustentam - ou pelo menos inspiram - o pensar e o fazer dos profissionais, militantes ou profissionais/militantes, hegemonicamente vinculadas à determinada matriz teórica existente no campo das ciências humanas e sociais.

Tais tendências nem sempre expressam fidelidade total a estas matrizes teóricas do conhecimento no campo da modernidade, nem mesmo se vinculam explicitamente à diversa tradição pós-moderna. Em muitas situações a relação não é sequer considerada, muito menos citada conscientemente, por seus adeptos. Lidam e consideram, frequentemente, fragmentos de diferentemente concepções acerca da realidade (orientações neopositivistas, neofuncionalistas, sistêmicas e de inspiração marxista, entre outras, estruturalistas ou não). Endossam, sem qualquer tipo de neutralidade (ainda que possam reivindica-la), orientações mais coerentes com certa tradição teórica ou ecléticas e pragmáticas utilizadas indiscriminadamente para pensar o mundo e agir sobre ele.

O leque de opções, aqui, é bastante extenso e diverso. Portanto, o termo "tendências teóricas" tem o exato sentido de expressar amplamente certa inspiração teórico-política, incorporada conscientemente ou não, com maior ou menor coerência e densidade, utilizada para responder a diversas demandas que afetam a realidade dos cubanos e cubanas, seus problemas cotidianos, nisto as demandas socialmente atribuídas ao Trabalho Social e aos trabalhadores sociais neste país.

Tendências de inspiração sistêmica (BERTALANFFY, 1980; LUHMANN, 2010), com perfis pós-modernos (LYOTARD, 2000), com ênfase em Marx e em parte de sua tradição ou em outras tradições teóricas diversas - com suas expressões calcadas ou não em formas de estruturalismo (COUTINHO, 2010) -, atuam nas Ciências Sociais e no Trabalho Social cubano na atualidade. A inspiração em fragmentos dessas tradições é nítida, mas não reproduz as mesmas mediações objetivamente dadas nos demais países latino-americanos que jamais vivenciaram qualquer processo que pudesse representar um projeto de inspiração socialista comparado ao cubano. Esse ingrediente, no mínimo, mesmo com as dificuldades objetivas atuais no campo das esquerdas e do projeto socialista-comunista, insere nesse debate aspectos específicos que não podem ser subestimados. 
Em relação ao Trabalho Social cubano, considerando a diversidade deste termo na llha (conforme anteriormente indicado), dois aspectos têm sido reafirmados desde o triunfo do "Movimiento 26 de Julio" em janeiro de 1959: seu caráter eminentemente prático-interventivo e sua ênfase comunitária - que não desconsidera a abordagem individual - com níveis formativos muito diversos. Essas foram as bases para que se constituíssem as várias denominações do Trabalho Social em Cuba: a) a formação das militantesvoluntárias de esquerda promovida pela Federação das Mulheres Cubanas; b) a formação técnica, de nível médio, fornecida - entre 1971 e 1998 - pelo Ministério de Saúde e pela "Escuela de Trabajadores Sociales de Psiquiatría"; c) a licenciatura em Sociologia com Especialização em Trabalho Social feita pelo Departamento de Sociologia da Universidade de Havana; d) o mestrado em Trabalho Comunitário viabilizado pela Universidad de Camagüey "Ignacio Agramonte Loynaz" (UC) y o Centro de Estudos Comunitários da "Universidad Central Martha Abreu de Las Villas"; e) bem como a proposta da "Escuela Emergente de Trabajadores Sociales" (2000), programa cuja formação esteve voltada aos jovens cubanos que cresceram a partir do legado deixado pelo "período especial" vivido durante toda a década de 1990 (hoje extinta - SILVA e CARMO, 2015). Todavia, cada uma destas denominações foi constituída e ou reorganizada por intencionalidades, objetivos e lógicas formativas muito diversas, seguramente emergenciais, mesmo que o foco central tenha sido (e ainda é - para as propostas em curso) a intervenção na realidade social com ênfase na abordagem comunitária sem desconsiderar os indivíduos e suas demandas.

Tratando especificamente das tendências teóricas existentes no Trabalho Social cubano, é preciso reconhecer que elas possuem, de uma forma ou de outra, um diálogo com certa tradição marxista não apenas incorporada a partir da aproximação da Ilha com a Internacional Comunista e o legado soviético, mas também constituída por meio da articulação disto com as esquerdas cubanas que já existiam antes de 1959, a história da luta contra a colonização espanhola simbolizada por José Martí e a presença hegemônica de Fidel Castro Ruz como comandante do legado revolucionário cubano. Esse processo formou-se e consolidou-se na correlação entre as forças sociais e partidos políticos que apoiaram o "Movimiento 26 de Julio", movimento este originalmente de perfil democrático-popular, anti-imperialista e de luta pela liberação nacional. ${ }^{8}$ Não possuiu, portanto, de início, um projeto socialista-comunista propriamente dito.

Ora, não há como descartar a forte influência marxista na trajetória mais recente de Cuba, ainda que seja absolutamente importante ressaltar que se trata de uma tradição heterogênea e, portanto, não advinda unicamente das fontes marxianas originais e ou de sua tradição mais refinada. Esse foi o legado que orientou, a partir de 1959, a formação das militantes-voluntárias de esquerda comprometida com a revolução popular lideradas pelos (as) guerrilheiros (as) de Sierra Maestra, bem como afinada com seus graduais desdobramentos que culminaram com a forte presença soviética na llha nos anos 1970 e 1980 . Um exemplo é Vilma Espín, importante quadro do Trabalho Social cubano, guerrilheira, esposa e companheira de Raúl Castro, que liderou a Federação das Mulheres Cubanas formando pessoas comprometidas com a erradicação do analfabetismo, com a melhoria das condições de saúde, com a ampliação dos direitos das mulheres, entre outras pautas que compuseram o aprofundamento do processo revolucionário cubano. ${ }^{9}$

Em conjuntura completamente diversa, mas na mesma direção, Fidel Castro criou a "Escuela Emergente de Trabajadores Sociales" em 2000, formação concentrada em três meses e voltada a jovens que enfrentavam os duros desdobramentos do período especial dos anos $1990 .{ }^{10} \mathrm{Houve}$, nesses dois casos, um compromisso militante com a defesa e manutenção do legado revolucionário cubano, utilizando um conjunto de procedimentos, instrumentos, técnicas que pudessem ter eficiência e eficácia prática na defesa do projeto cubano inserido na tradição marxista.

Não se trata, então, de tendências com certa base teórica voltadas propriamente à formação de profissionais em Serviço Social-Trabalho Social, mas de formação militante, não necessariamente científica, orientada por princípios e valores socialistas que sustentaram a formação do sujeito social-comunitário cubano. Neste contexto, o que predomina é o compromisso ético-político com a causa revolucionária, empenhado com o sucesso do projeto, sua manutenção, ainda que possa mesclar orientações e tendências divergentes que, submetidas ao rigor cientifico, poderiam ser questionadas por determinada tradição teórica (inclusive por Marx e pelos marxistas). 
Em relação aos outros três níveis de formação em Trabalho Social em Cuba, ou seja, aqueles vinculados às universidades de Havana, Universidad de Camagüey "Ignacio Agramonte Loynaz" (UC), o Centro de Estudos Comunitários da "Universidad Central Martha Abreu de Las Villas" e o de formação técnica mantida pelo Ministério de Saúde, o processo se apresenta com características muito diversas. Em todas estas experiências as características apontadas nos casos anteriores estão presentes (a abordagem práticointerventiva comunitária e a influência de certo tipo de marxismo), embora mediadas por tradições e tendências teóricas diversas e, em determinadas situações, nitidamente com perfil eclético (nem sempre assumido).

A formação técnica feita entre 1971 e 1998, comandada pelo Ministério de Saúde de Cuba e pela "Escuela de Trabajadores Sociales de Psiquiatría", possui ênfase médica, individual e psicossocial incontentável (em que pese a abordagem universal da saúde cubana). É a partir deste patamar que a preocupação eminentemente interventiva e comunitária é destacada, inclusive com experiências práticas interessantes e inovadoras, mas com uma fundamentação teórico-científica precária, excessivamente instrumental e eclética.

Elas associam um discurso oficial marxista e de defesa da revolução, traços da literatura da psicologia/ psiquiatria e da fundamentação metodológica positivista-funcionalista/sistêmica incorporadas e importadas, sobretudo, da medicina. Há, ao mesmo tempo, o reconhecimento desta debilidade enfrentada - com limites - por boa parte do Serviço Social/Trabalho Social latino-americano, a partir do Movimento de Reconceituação nos anos 1960 e 1970.

O Trabalho Social cubano não vivenciou esse processo por dentro, já que o projeto revolucionário impôs à profissão outras demandas legítimas e necessárias, embora eminentemente operativas. Nesse complexo cenário, a profissão reforçou seu caráter instrumental-interventivo, mesmo porque estava associada, antes do início do processo revolucionário, a ações de cunho puramente assistencialista com abordagem predominantemente de ajuda-social individual (diga-se de passagem, trajetória muito próxima a toda América-Latina).

Embora o governo revolucionário cubano tenha feito a crítica a essa realidade em que se inseria a profissão, não houve espaço para redirecionar cientifica e criticamente o Trabalho Social em Cuba (e os motivos aqui foram complexos e diversos), impossibilitando o estímulo a uma formação profissional para além de sua dimensão técnico-operativa com traços ecléticos advindos, sobretudo, da medicina e da psiquiatria. A complexidade deste processo pode ser destrinchada considerando dois aspectos importantes: a) o entendimento do governo revolucionário de que o Trabalho Social na llha, antes de 1959, era comprometido com a manutenção da desigualdade social até então existente; b) a compreensão de que as tarefas revolucionárias seriam cumpridas por toda a sociedade cubana, não sendo necessário requalificar os quadros profissionais da profissão; c) a visão revolucionária entendeu que a profissão tinha um caráter meramente técnico-instrumental e que ele deveria estar a serviço da pauta revolucionária. Esse entendimento trouxe perdas tanto à profissão quanto à revolução; d) o lugar das ciências humanas e sociais para o projeto revolucionário como instância que deveria estimular a tradição cubano-marxista e enfrentar tendências antirrevolucionárias contidas no país (o que era um combate feito de todos os lados durante a Guerra Fria). Destaca um quadro influente do Trabalho Social cubano da área de saúde:

El Trabajo Social en nuestro contexto nacional ha renovado su accionar apoyado en la metodología primordial de intervención (IAP-Investigación-Acción Participativa), permitiéndonos afrontar los problemas sociales en los diferentes escenarios de manera interaccionista. Sin embargo, con la carencia teórica y la debilidad metodológica y epistemológica que ha padecido nuestra profesión durante años, ciertamente se ha privilegiado el desarrollo de saberes fundados en la intervención, más que de conocimientos respaldados en una investigación sistemática y sólida. (...) Pensamos que el estado actual del ejercicio profesional se está orientando hacia una actuación más dialéctica, interactiva y crítica, potenciadora de las capacidades humanas, que busca tanto satisfacer necesidades como estimular capacidades. (...) Pensamos que es nuestra tarea comenzar a privilegiar el trabajo micro social, desde una perspectiva 
integral que implica el reconocimiento de la múltiples y complejas dimensiones que hacen parte de la realidad social en la cual debe actuar el Trabajo Social. Intervenir en forma integral, implica también concebir al sujeto con diversos requerimientos, lo que demanda la atención de los mismos en el marco de esa complejidad. (...) Debemos comenzar a ampliar nuestras reflexiones y entender a la persona con capacidad de transformar su situación; hacer uso de la participación y la movilización de los actores sociales a través de la metodología primordial para el Trabajo Social renovado (IAP); tratar de ir desde el propio asistencialismo y providencia de recursos materiales hasta aquellas acciones que impliquen movilización; pasar de una reforma individual a una transformación social (JUBÁN, 2005, p. 146).

O trecho acima reproduzido reconhece as debilidades teóricas do Trabalho Social Cubano, valoriza a formação profissional, ainda que situe isso apenas no nível das experiências interventivas aí promovidas (o que não é menos importante). Nota-se, todavia, que os termos "dialético", "interativo" e "crítico" são adotados sem muita nitidez, mediados pelas demandas emergenciais e imediatas do país, momento em que se reivindica certo "exercício profissional" que prioriza a intervenção "microssocial", entendida como um tipo de abordagem estimuladora das "capacidades humanas" que auxilia a "satisfação de necessidades".

Ora, trata-se de uma demanda societária imposta pelo atual momento à Cuba, inspirado no espírito empreendedor e empoderador das pessoas na resolução de problemas, com traços sistêmicos que priorizam o indivíduo, destacam a importância de sua rede comunitária no trato de "múltiplas e complexas dimensões" em um espaço dito "complexo", enfatizando uma orientação integral, interativa, comunicativa e participativa (IAP - investigação-ação participativa). A ênfase principal está na dinâmica individual e microssocial, na mudança de atitude das pessoas, centrada na mobilização para a solução de suas dificuldades, tendo a prática como foco principal para mobilizar o indivíduo por meio de processos participativos e coletivosgrupais geradores de uma "reforma individual" que gere "transformações sociais" para além do que é visto como "assistencialismo" e "providência de recursos materiais".

O caráter técnico-operativo que sempre foi hegemônico na Ilha, ainda que afinado com objetivos e pautas revolucionárias, reatualiza o que tradicionalmente foi solicitado ao Trabalho Social desde sua gênese antes do triunfo da Revolução em 1959 e na era monopolista do capital (NETTO, 1992): a gestão das refrações da questão social por meio de micro-espaços e de micro atuações estimuladoras das habilidades individuais, das iniciativas das pessoas. Trata-se de um procedimento que reforça ações historicamente situadas no campo mais conservador da profissão em um cenário de amenização da pauta socialista provedora de recursos, reposicionando a profissão na direção da gestão individual da questão social em ascensão na atual realidade cubana marcada por restrições do Estado Social. ${ }^{11}$ O procedimento, aqui, deveria ser outro: resgatar a tradição socialista cubana (peculiar a este país), seu perfil universal e comunitário (nisto os indivíduos sociais), adensando a formação teórico-crítica enriquecedora de práticas criativas e próximas às demandas populares (o que já é uma tradição em Cuba).

Não há como empreender isso estabelecendo como foco principal a dinâmica individual, a mobilização dos indivíduos na solução de dificuldades, bem como sem a qualificação intelectual mediada pelas universidades (embora não somente centrado nelas), pelo estudo e pela pesquisa permanentes (não apenas vinculados aos espaços da prática), em tempos de ofensiva do capital na Ilha. Situa-se, aí, um importante espaço de defesa da tradição socialista cubana no campo particular das profissões.

Há de se destacar, todavia, outros níveis de inserção do Trabalho Social em Cuba, diretamente vinculados à esfera universitária, adensada na segunda metade dos anos 1990, ainda que o Trabalho Social cubano - como profissão - não exista como área de conhecimento e de formação dentro das universidades. O primeiro deles esteve e ainda está ligado ao Departamento de Sociologia da Universidade de Havana.

Este espaço formativo manteve um curso nesta área com uma "saída" (especialização) em Trabalho Social. Isto permitiu não apenas que discentes de sociologia fizessem essa opção ao longo da carreira, como também estimulou que profissionais que mantinham proximidade com o Trabalho Social - ou tivessem uma formação técnica na área - pudessem adensar seus estudos na universidade, também nos níveis de 
mestrado e de doutorado. Embora tenha sido uma iniciativa pontual e com limites de alcance, esta proposta foi de grande relevância. ${ }^{12}$

Ela permitiu que quadros promissores do Trabalho Social cubano desenvolvessem seus estudos em nível de pós-graduação, estimulou dois convênios internacionais mobilizando apoio governamental (Suécia e Brasil), bem como desencadeou aproximações com o Ministério do Trabalho e Seguridade Social. Tem promovido, ainda, cursos de curta duração, denominados "diplomados", importantes espaços de aproximação com profissionais de nível técnico que atuam na área da seguridade social. Lamentavelmente, por questões internas, essa proposta não se efetivou nem se articulou com a área de saúde e seus profissionais.

Neste nível há, em curso, um nítido processo de qualificação do debate sobre o Trabalho Social, com forte viés sociológico como área de conhecimento consolidada no campo das Ciências Sociais. Um amplo e diverso debate é recuperado, considerando uma variada tradição teórica que transita da heterogênea pós-modernidade a certa literatura marxista-leninista-cubana.

É interessante ressaltar, todavia, que as referências utilizadas no âmbito do Trabalho Social em Cuba até 2011 se centraram, quase que unicamente, em autores tais como Ezequiel Ander-Egg, Herman Kruse, Ricardo Hill, Seno Cornely, Renné Dupont, Norberto Alayón, entre outros, distante de referências mais recentes. Entretanto, o acesso à literatura brasileira atual e de outros países latino-americanos, tem se adensado nos últimos seis anos, o que tem impactado positivamente nos debates atuais sobre o Trabalho Social Cubano. Tratando do que denominam de "reinstitucionalização do Trabalho Social em Cuba", Gutiérrez e Barroso tecem informações relevantes:

\begin{abstract}
Al revisar las funciones del trabajador social en cualquier texto aparece siempre la actividad investigativa, aún insuficientemente desarrollada en las condiciones del país. No olvidar que José Paulo Netto (2005) insiste en que la investigación es indispensable al Trabajo Social, si la profesión quiere mantener su estatus universitario. Agrega que el profesional debe apropiarse críticamente del conocimiento existente sobre el problema en cuestión, el específico del cual se ocupa; dominar la bibliografía teórica y la documentación legal; sistematizar las experiencias y modalidades de intervención institucionales; manejar las formas de control social, así como el papel de los intereses de los usuarios y de los sujetos colectivos involucrados. Lo anterior debe ser un proceso continuo y renovado si queremos incorporar el método en Marx (GUTIÉRREZ e BARROSO, 2016, p. 192-193).
\end{abstract}

As questões aqui ressaltadas pelas docentes-pesquisadoras cubanas são de grande destaque. Elas resgatam pelo menos três aspectos relevantes: a) a importância da pesquisa para a formação profissional e intelectual dos trabalhadores sociais (dentro e fora das universidades, ao mesmo tempo); b) a ênfase no estudo permanente como base insubstituível para a formação de intelectuais (nisso a ampla diversidade de referências teóricas com as quais é necessário lidar criticamente); c) a importância da recuperação do legado marxiano, nisso seu método, como procedimento importante e afeito particularmente à tradição revolucionária cubana.

Sob estas bases seria possível redirecionar a formação profissional do Trabalho Social em Cuba, valorizando o legado construído e adensando-o coerentemente inspirado na ampla tradição revolucionária derivada de Marx. Há de se destacar, todavia, o perigo de não atribuir ao academicismo e ao sociologismo as bases centrais para a inserção do Trabalho Social como área de conhecimento nas universidades. A necessária densidade teórica é ingrediente imprescindível à qualificação profissional e intelectual, embora não seja suficiente.

A militância e a práxis social, como compromisso ético-político com projetos societários orientandos pela emancipação humana (MARX, 2005, p. 42), são traços essenciais para que não se identifique nem se faça a ruptura absoluta entre militância e profissão. Profissões se estruturam sob bases limitadas, objetivamente dadas, embora seja absolutamente essencial que elas estejam sintonizadas com projetos societários que certamente extrapolam suas fronteiras.

Cenário não muito diferente, mas com particularidades nada desprezíveis, está presente no mestrado em Trabalho Comunitário viabilizado pela “Universidad de - Ignacio Agramonte Loynaz" (UC) e na experiência 
do Centro de Estudos Comunitários da "Universidad Central Martha Abreu de Las Villas". ${ }^{13}$ Embora diversos e situados em cidades diferentes (Camagüey y Santa Clara), esses dois centros formativos envolvem profissionais de várias áreas articulando certa inspiração marxista com o heterogêneo debate pós-moderno.

As produções destes centros de formação revelam um debate mais intenso sobre a abordagem comunitária, com o compromisso ético-social e com a emancipação humana (MARX, 2005). ${ }^{14}$ Guardadas as diferenças qualitativas e históricas necessárias, há nestes estudos (COLETIVO DE AUTORES, 2011 e 2012) certa aproximação e compromisso social com as demandas populares presentes, por exemplo, nas primeiras abordagens críticas do Serviço Social brasileiro como parte de sua renovação e da reconceituação latinoamericana. O vínculo orgânico com a classe trabalhadora presente nos estudos brasileiros do final dos anos 1970 e toda a década de 1980 (hoje seguramente adensados no que se convencionou caracterizar como "Projeto Ético-Político Profissional"), aparece nestes centros de formação cubanos como um compromisso com os ideais da revolução resgatando temas atuais inspirados pela emancipação social do povo cubano e de seus segmentos mais oprimidos: comunidade LGBTi, mulheres, famílias, juventude, assuntos relacionados a grupos atingidos pela crise econômica, nisto as questões institucionais, governamentais, ambientais, as violências e as políticas e serviços públicos no pais. Como na experiência brasileira, enfatiza-se uma preocupação científica comprometida com a delimitação do objeto de estudo do Trabalho Social e com a adoção de procedimentos científicos para uma atuação profissional emancipatória (o que também está presente na Universidade de Havana), longe de procedimentos centrados unicamente-prioritariamente na dinâmica individual e no seu entorno sistêmico para a solução de problemas.

Há de se destacar, todavia, que esse debate possui problemas a serem enfrentados no âmbito da formação profissional: a) ele está ausente naqueles segmentos profissionais que atuam diretamente junto à população (particularmente na área de saúde), formação centrada na dimensão puramente técnicooperativa e em fragmentos isolados de diferentes matrizes teóricas do conhecimento; b) pode reforçar certa visão centrada na perspectiva das ciências especializadas de viés sociológico que frequentemente separa e hierarquiza teoria e prática, endossando certo viés academicista que enfatiza o comando da "razão científica" sobre a realidade; c) se expressa, em determinados momentos, imersa em certo tipo de cientificização marxista que recupera dimensões importantes da análise dialética (contradição, história, historicidade, etc..), mas ainda manejada a partir de uma visão cientifico-mecanicista mais afeita a certa tradição positivista. Todavia, a indicação destes pontos críticos não invalida as importantes experiências aqui destacadas, sobretudo nos centros de formação que estimulam o diálogo entre universidade-comunidade (particularmente no programa comunitário mantido em Camagüey, no Centro de Estudos de Santa Clara e na Universidade de Havana), reivindicando a necessidade de um debate científico para a qualificação do Trabalho Social cubano.

Mais do que limites, estes espaços expressam preciosas potencialidades que podem e devem ser amadurecidas e adensadas. De nossa parte se encontram, nestes espaços formativos, as melhores condições para o desenvolvimento de um Trabalho Social crítico fiel à tradição revolucionária da Ilha. Destaca Ramón Rivero Pino:

Para los profesores-investigadores del Centro de Estudios Comunitarios de la UCLV, el Trabajo Social sí constituye y na disciplina científica, que aunque en formación, tiene definido un objeto de estudio particular: las regularidades que tienen lugar en el espacio de interacción de las necesidades sociales y las respuestas científicas e institucionales (políticas y servicios sociales) para su satisfacción. Ese espacio es de praxis (reflexión y acción). Por ello al Trabajo Social le corresponde tanto la construcción de saberes, de teorías y métodos como su aplicación, por lo que puede ser catalogada como disciplina científica y como profesión (PINO, 2011, p. 11).

Na ênfase dada por Enrique Gómes Cabezas, também com nítida preocupação formativa-científica, se expressa mais intensamente uma perspectiva embebida pelos ideais revolucionários cubanos (orientadas pelas observações de Fidel Castro). ${ }^{15}$ Para ele, o Trabalho Social em Cuba deve imbricar-se ao projeto da Revolução Cubana, articulando compromisso ético-político com "processos educativos e de conscientização", 
com a "emancipação", bem como com a competência teórico-prática profissional em uma sociedade revolucionária que enfrenta transformações.

A ênfase participativa e coletiva contra as expressões capitalistas do "mundo globalizado" e o individualismo nela implícito, sustenta-se em um compromisso ético-político articulado a uma formação profissional competente capaz de debater o sentido atual do Trabalho Social no país. É nesse contexto que o trabalho comunitário é reivindicado na "construção de relações comunitárias", para além do que Henrique Cabezas denomina de egoísmo como hegemonia cultural que fragmenta as relações sociais. Já existe, aqui, inspiração no legado crítico do Serviço Social brasileiro, formalmente inaugurado pelo Método de Belo Horizonte, ainda que se deva considerar, evidentemente, as particularidades de Cuba e as atuais transformações em que passa a llha na historicidade em curso.

El proyecto de la Revolución Cubana demanda de una acción social centrada en la construcción de relaciones comunitarias, por sobre el egoísmo, el hegemonismo cultural y la fragmentación social que prevalecen en el mundo globalizado de hoy y que se reproducen a partir de la estimulación constante de los instintos individualistas de los seres humanos. La sociedad nueva, lo será por las nuevas relaciones sociales que se constituyan, caracterizadas por su simetría y horizontalidad, que potencien la participación y la colaboración; que sean verdaderamente humanas y solidarias. Estas relaciones no se desarrollan de manera espontánea y reclaman de procesos educativos y de concientización, que demandan hoy de un profesional del trabajo social que ejerza una mediación éticamente comprometida y profesionalmente competente. (...) El trabajo social en Cuba tiene el reto de crecer como ejercicio profesional y asumir, como proyecto ético-político comprometido con la emancipación, los desafíos que enfrenta el desarrollo social en el proceso revolucionario. Desde esa posición es imprescindible problematizar sobre su papel en la sociedad, los valores profesionales y el sentido de su práctica (CABEZAS, 2011, p. 275 e 277).

A sobrevivência do Trabalho Social crítico cubano e de todos aqueles existentes em outras regiões do globo (inspirados em níveis crescentes de emancipação social), depende de elementos que articulem iniciativas a eles internas (sobretudo sua qualificação teórica, científica e ético-política), alterações operadas no campo das esquerdas em escala mundial, a construção de alternativas e projetos progressistas capazes de articular anticapitalismo (como crítica ao capital), anti-imperialismo como crítica à dependência, bem como alternativas de resistência potenciadas em esferas locais, regionais, nacionais e continentais relacionadas entre si e internacionalistas. O caminho, portanto, inclusive para o Trabalho Social cubano, não é endógeno embora contemple importantes ações situadas no âmbito profissional.

\section{Comentários finais}

O estudo sobre as tendências teóricas hoje em curso no "Trabajo Social" (nas suas diversas formas de manifestação) é tarefa essencial para adensar o debate crítico na área. Não se trata, em absoluto, de uma empreitada unicamente acadêmica centrada na lógica de pesquisadores que se alimentam de temas desnecessários e pouco afeitos à "prática".

Ao contrário, trata-se de procedimento essencial para o adensamento teórico como exercício de reconstrução mental do materialmente posto, cujo ponto de partida é sempre a própria realidade que estabelece as bases para a reprodução da "questão social" e suas refrações. Essa empreitada, que já era urgente, tem se reafirmado em tempos de adensamento da pauta do grande capital por todo mundo e particularmente pelo continente latino-americano.

O recrudescimento dos conservadorismos e reacionarismos, o adensamento das práticas de genocídio e extermínio de segmentos desapropriados permanentemente pelo capital, o crescimento da extrema direita, as inúmeras ações de apartheid social que atingem mulheres, negros, comunidade LGBT, moradores de rua, entre outros segmentos, devem ser combatidos seguindo dois caminhos insuprimíveis: a) estudo, 
análise e crítica radical de suas teses centrais; b) projetos efetivos, reais, que se contraponham objetivamente a tais orientações.

Cuba parece reforçar alguns aspectos importantes neste nível que devem ser aqui destacados: o compromisso com a universalização de direitos, particularmente a saúde e a educação; a consciência de que o Estado exerce papel importante, embora não onipotente e único, na gestão do modelo econômico do país e na melhoria dos níveis de desigualdade na Ilha; a importância de incluir no projeto de inspiração socialista temas necessários a níveis crescentes de emancipação humano-social, tais como reconhecimento dos direitos das mulheres e da comunidade LGBT (o primeiro adensando o que o projeto revolucionário de 1959 já havia estimulado; o segundo, revendo equívocos históricos).

Cuba e o Trabalho Social cubano encontram-se em uma encruzilhada que supõe, ao mesmo tempo, possibilidades objetivas e, até certo ponto, decisões e escolhas específicas em debate na llha. Como o Trabalho Social não fala apenas por si, embora também possa tecer suas considerações e forcejar direções e opções (e isso não é menos importante), ele depende substancialmente das decisões possíveis do país e de um contexto internacional favorável a projetos humanistas de esquerda. Nisto, as sábias palavras de Che sem as quais a capitulação triunfará:

La teoría y la práctica constituyen una unidad que hay que saber dominar. (...) Todo esto sobre la base de la crítica y la autocrítica constante, descubriendo todas las fallas y todos los problemas, sabiendo aceptar la crítica, y sabiendo criticarse también es importante, y haciendo siempre un análisis critico del trabajo propio para poder darse cuenta de todos los errores que hemos cometido y enmendarlos (GUEVARA, 2009, p. 26).

\section{Referências}

ALAYÓN, Norberto (org.). Trabajo Social latinoamericano: a 40 años de la reconceptualización. Buenos Aires: Espacio Editorial, 2005.

BARROSO, Lourdes Urrutia; GUTIÉRREZ, Teresa Muñoz. El desarrollo del trabajo social en Cuba: profesionalización y práctica. Trabajo Social en Cuba y Suecia. La Habana: Ministerio de Educación Superior-talleres gráficos de Geocuba, 2004, p. 45-67. https://doi.org/10.14482/esal.2.10105

BERTALANFFY, L. Von. Teoría general de los sistemas. México: Fondo de Cultura Económica, 1980.

BORGIANNI, Elisabete; MONTAÑO, Carlos (org.). Coyuntura actual, latinoamericana y mundial: tendencias y movimientos. São Paulo: Cortez Editora, 2008.

BORON, Atilio A. América Latina en la geopolítica del imperialismo. 2. ed. Buenos Aires: Ediciones Luxemburgo, 2014.

COLECTIVO DE AUTORES. El trabajo comunitario: alternativa cubana para el desarrollo social. Camagüey: Editorial Acana y Ediciones Universidad de Camagüey, 2004.

COLECTIVO DE AUTORES. El Trabajo Social como profesión. Valores y principios éticos. La Habana: Ed. Félix Varela, 2008.

COLECTIVO DE AUTORES. El trabajo social. Su aporte a la emancipación humana. Santa Clara, Villa Clara, Cuba: Editorial Feijóo: Centro de Estudios Comunitarios de la Universidad Central “Marta Abreu” de Las Villas, 2011. https://doi. org/10.22209/rt.v42n1a03

COLECTIVO DE AUTORES. El trabajo social. Su aporte a la emancipación humana. Santa Clara, Villa Clara, Cuba: Editorial Feijóo: Centro de Estudios Comunitarios de la Universidad Central "Marta Abreu” de Las Villas, 2012. https://doi. org/10.22209/rt.v42n1a03

COUTINHO, Carlos Nelson. O estruturalismo e a miséria da razão. 2. ed. São Paulo: Expressão Popular, 2010. https://doi. org/10.11606/issn.2318-8863.discurso.1973.37757 
FERNANDES, Florestan. Capitalismo dependente e classes sociais na América Latina. São Paulo: Global, 2009.

GIANA, Sergio Daniel. Decadencia ideológica y Trabajo Social: crítica al debate contemporáneo profesional. La Plata: Editorial Dynamis, 2015.

GÓMEZ CABEZAS, Enrique. El trabajo social en el pensamiento de Fidel Castro Ruz. Cuadernos do Ceam, Brasília, DF, ano 8, n. 35, p. 227-246, set. 2013. https://doi.org/10.24850/j-tyca-2020-02-09

GÓMEZ CABEZAS, Enrique. El Trabajo Social: una demanda profesional en Cuba. Tese (Doutorado em Ciências Sociais) La Habana, 2015.

GÓMEZ CABEZAS, Enrique. Premisas para el desarrollo del trabajo social en el contexto cubano actual [online], 2012.

GÓMEZ CABEZAS. Retos para el Trabajo Social en Cuba. In: COLECTIVO DE AUTORES. El trabajo social. Su aporte a la emancipación humana. Santa Clara, Villa Clara, Cuba: Editorial Feijóo: Centro de Estudios Comunitarios de la Universidad Central “Marta Abreu”de Las Villas, 2011, p. 263-279. https://doi.org/10.24850/j-tyca-2020-02-09

GUEVARA, Ernesto Che. Retos de la transición socialista en Cuba (1961-1965). Ciudad de México: Centro de Estudios Che Guevara: Ocean Sur, 2009. https://doi.org/10.18050/rev.mg.v35i2.1411

GUTIÉRREZ, Teresa Muñoz; BARROSO, Lourdes Urrutia. Pensar acerca de la reinstitucionalización del Trabajo Social en Cuba (2011-2015). Política Social e Serviço Social - Brasil e Cuba em debate. São Paulo: Editora Veras, 2016, p. 179-200. (Coleção Coletâneas, n. 6).

LENIN, V. I. O imperialismo - fase superior do capitalismo. Tradução de Leila Prado. São Paulo: Centauro, 2008.

LUHMANN, Niklas. Introdução à teoria dos sistemas. Tradução de Ana Cristina Arantes Nasser. 2. ed. Petrópolis: Vozes, 2010. (Coleção Sociologia).

LYOTARD, François. A condição pós-moderna. Rio de Janeiro: José Olympio, 2000.

MARINI, Ruy Mauro. América Latina, dependencia y globalización. Bogotá: CLACSO y Siglo del Hombre Editores, 2008.

MARX, Karl. A questão judaica. 5. ed. São Paulo: Centauro, 2005.

MARX, Karl. O capital: crítica da Economia Política. São Paulo: Abril Cultural, 1984. v. 1, tomo 2.

MARX, Karl. O método da economia política. In: FERNANDES, Florestan (org.). Marx e Engels - História. 3. ed. São Paulo: Ática, 1989. (Textos originais de Marx e Engels).

MARX, Karl; Engels, F. A ideologia alemã. São Paulo: Boitempo Editorial, 2007.

MASTRAPA, Ernel Gonzáles; QUINTANA, Osnaide Izquierdo. Cuba: modelo de desarrollo e inserción en el mercado internacional. Antecedentes, desafíos y oportunidades en el actual escenario de mundialización del capital. Política Social e Serviço Social - Brasil e Cuba em debate. São Paulo: Editora Veras, 2016, 39-60. (Coleção Coletâneas, n. 6). https://doi. org/10.18356/23ff8512-es

NETTO, José Paulo. Ditadura e serviço social: uma análise do serviço social no Brasil pós-64. São Paulo: Cortez, 1991.

NETTO, José Paulo. Capitalismo monopolista e serviço social. São Paulo: Cortez, 1992.

PINO, Ramón Rivero. El objeto de estudio e intervención del Trabajo Social. In: COLECTIVO DE AUTORES. El trabajo social. Su aporte a la emancipación humana. Santa Clara, Villa Clara, Cuba: Editorial Feijóo: Centro de Estudios Comunitarios de la Universidad Central “Marta Abreu”de Las Villas, 2011, p. 9-21. https://doi.org/10.22209/rt.v42n1a03

RAMONET, Ignacio. Fidel Castro - biografia a duas vozes. São Paulo: Boitempo Editorial, 2006.

SILVA, José Fernando Siqueira da; CARMO, Onilda Alves do. Notas sobre o Trabalho Social cubano. Serv. Soc. Soc., [s. I.], n. 121, p. 143-162, 2015. https://doi.org/10.1590/0101-6628.017

SILVA, José Fernando Siqueira da. Serviço social: razão ontológica ou instrumental? Revista Katálysis, Florianópolis, n. 1, v. 16, jan./jun., p. 72-81, 2013a. https://doi.org/10.1590/s1414-49802013000100008 
SILVA, José Fernando Siqueira da. Serviço social: resistência e emancipação? São Paulo: Cortez, 2013b.

SILVA, José Fernando Siqueira da. Serviço Social e tendências teóricas atuais. Rev. katálysis, Florianópolis, v. 20, n. 1, p. 6574, abr. 2017. Disponível em: http://www.scielo.br/scielo.php?script=sci_arttext\&pid=S1414-49802017000100065\&lng=en \&nrm=iso. Acesso em: 16 jun. 2017. https://doi.org/10.1590/1414-49802017.00100008

SILVA, J. F. S. da; GUTIÉRREZ, Teresa del Pilar Muñoz (org.). Política Social e Serviço Social - Brasil e Cuba em debate. São Paulo: Veras, 2016. (Coleção Coletâneas, n. 6).

\section{Notas}

${ }^{1}$ O texto ora apresentado é parte da pesquisa - em curso até novembro de 2019 (processo FAPESP 2007/14497-5) - denominada "Serviço Social e América Latina: tendências teóricas atuais", estudo interinstitucional que envolve docentes-pesquisadores e discentes do curso de graduação da UNESP-Franca e dos Programas de Pós-graduação em Serviço Social da Pontifícia Universidade Católica de São Paulo (PUC) e Universidade Federal de São Paulo (UNIFESP). Conta ainda com dois representantes de outras duas universidades federais, Universidade Federal do Triângulo Mineiro (UFTM) e Universidade Federal de Brasília (UNB). Ademais, é composta por pesquisadores (as) associados (as) da Universidad de Chile (UC), Universidad de la República (UDELAR), Universidad Nacional de Asunción (UNA), Universidad Nacional de Luján (UNLU), Universidad de la Habana (UH) e Universidad Nacional de Costa Rica.

2 O estudo detalhado nos três livros de "O Capital" é revelador de uma tendência objetivamente constatada e reconstruída teoricamente por Marx. A teoria, como reconstrução mental do materialmente posto, não se apresenta como acabada, mas como processo material transposto à cabeça sob dadas condições sócio históricas. Portanto, não há aqui espaço para dogmas.

3 Nunca é demais lembrar que deriva daqui e tese de José Paulo Netto que localiza, muito precisamente, a gênese do Serviço Social como profissão na fase monopolista do capital (NETTO, 1992).

${ }^{4}$ Diga-se de passagem, uma característica das burguesias nacionais associadas ao capital estrangeiro: golpistas, antinacionais, regressivas, antidemocráticas, subservientes e avessas a qualquer tipo de reforma social que, ao menos, minimize a desigualdade social. Não se trata, aqui, de um ingrediente moral; a sua natureza é determinada pela sua posição social no jogo das relações capitalistas mundiais. Os recentes golpes e ou ataques às economias não alinhadas aos EUA, articulados sob o manto da democracia formal e de suas instituições, é prova de que velhos procedimentos persistem com outra roupagem.

${ }^{5}$ Grifos do autor.

${ }^{6}$ Sobre esse momento, consultar Mastrapa e Quintana in Silva e Gutiérrez (2016, p. 47-52).

7 O Projeto de Constituição da República de Cuba, aprovado no dia 22 de junho de 2018 no primeiro período ordinário de sessões da $9 a$ Legislatura da Assembleia Nacional do Poder Popular (ANPP), expressa essa tendência. Todavia, ao contrário do que foi amplamente divulgado pela imprensa burguesa internacional, não se trata de uma conversão à economia de mercado - em que pese as alterações de flexibilização liberal que foram submetidas à consulta popular -, mas procedimento necessário à sobrevivência econômica do país no atual cenário mundial. Não se trata, portanto, sob o nosso ponto de vista, pelo menos imediatamente, da derrota definitiva do horizonte comunista para o país e do fim da transição socialista na Ilha.

${ }^{8}$ Nunca é demais destacar: para o imperialismo dos EUA, como insistia Fidel, não havia espaço nem mesmo para um projeto nacionalista (nacional-desenvolvimentista, de fato). Seguramente não havia, nunca houve, não há e não haverá (para qualquer forma de imperialismo).

${ }^{9}$ Sobre a Federação das Mulheres cubanas consultar: http://old.operamundi.com.br/dialogosdosul/papel-primordial-das-mulherescubanas/12092014/ Sobre Vilma Espín, verificar: https://www.novacultura.info/single-post/2016/04/08/Vilma-Esp\%C3\%ADn-paradigmapara-as-mulheres-cubana.

${ }^{10}$ Vale destacar que o coordenador nacional deste programa, criado por Fidel Castro, foi Enríque Javier Gómes Cabezas, a nosso ver um dos quadros atuais mais promissores do Trabalho Social crítico em Cuba. Outras investigadoras em Ciências Humanas e Sociais, algumas delas com algum tipo de formação em Trabalho Social, são profundas conhecedoras desta área em Cuba: Professora Doutora Teresa del Pilar Muñoz Gutiérrez, Professora Dra. Clotilde Proveyer Cervantes, Professora Mestra Lourdes de Urrutia Barroso (ambas docentes do Departamento de Sociologia da Universidad de La Habana) e Professora Doutora Mirtha Juliana Yordi García (Universidade de Camagüey), são alguns exemplos.

${ }^{11}$ Trata-se de um equívoco tomar a experiência do Trabalho Social cubano unicamente pelo viés da saúde. Os tradicionais congressos internacionais promovidos pelos trabalhadores sociais da saúde cubanos, guardada a sua importância, acabaram generalizando apenas uma parte do que de fato se constitui o Trabalho Social neste país.

${ }^{12}$ Coordenada pelas professoras Teresa Muñoz Gutiérrez, Lourdes de Urrutia Barroso e Clotilde Proveyer Cervantes.

${ }^{13}$ Conforme observado pela Professora Dra. Gabriela Abrahão Masson em vista à llha em fevereiro de 2019, docente do curso de Serviço Social da Universidade do Triângulo Mineiro e pesquisadora associada à equipe de estudos do projeto FAPESP 2017/14497-5, existe, na cidade de Santa Clara - como em outras regiões de Cuba - um curso técnico de 3 anos mantido, desde 1984, pelo "Instituto Júlio Trigo Lopes", com formação em saúde voltada ao Trabalho Social. Há, inclusive, um curso de pós-graduação em Saúde vinculada à "Universidad Central Martha Abreu de Las Villas" que certamente dialoga com o Trabalho Social.

${ }^{14} \mathrm{~A}$ referência, aqui, é feita a partir das publicações que têm orientado a articulação de investigadores destes dois espaços formativos situados mais para a região centro-oriental da llha. Seguramente existem dissensos nesse grupo e enfoques que divergem da abordagem aqui referenciada.

${ }^{15} \mathrm{O}$ autor atuou diretamente na coordenação do programa criado pelo governo cubano, denominado "Escuela Emergente de Trabajadores Sociales", destinado à juventude cubana a partir dos anos 2000. Fidel Castro teve participação direta na criação da proposta que visava formar a juventude, em tempos de profunda crise vivida sob os espólios do período especial. Tais jovens eram formados para atuar nas localidades empobrecidas em decorrência da crise dos anos de 1990. Guardadas as polêmicas deste processo, que não são poucas, havia nítida preocupação formativa afinada ao socialismo cubano (nisto um potencial crítico nada desprezível, ainda que amplamente discutível), 
bem como uma necessidade objetiva: oferecer trabalho aos jovens com dificuldades para ingressar produtivamente no mercado de trabalho. Sobre a trajetória atual de Enrique Cabezas, consultar http://www.cips.cu/tag/enrique-gomez/.

Submetido em: $19 / 08 / 2018$

Aprovado em: 09/11/2019.

Publicado em: 10/02/2020.

\section{Correspondência para:}

Universidade Estadual Paulista (UNESP)

Faculdade de Ciências Humanas e Sociais - Departamento de Serviço Social

Av. Eufrásia Monteiro Petráglia, 900 - Jd. Dr. Antonio Petráglia

14409-160, Franca, SP, Brasil

\section{Autor:}

José FERnANDo SIQUeIRA DA SILVA

Assistente Social. Possui pós-doutorado pela Universidade Nacional de La Plata (2015/Argentina).Livre-docente pelo Departamento de Serviço Social da Universidade Estadual Paulista Franca (UNESP). Professor Associado do Departamento de Serviço Social da UNESP-

Franca e docente colaborador do Programa de Pós-Graduação em Serviço Social e Políticas Sociais da Universidade Federal de São Paulo (UNIFESP). Pesquisador do Conselho Nacional de Desenvolvimento Científico e Tecnológico (CNPq) na área de Serviço Social desde 2009.

Orcid: http://orcid.org/0000-0003-1040-9558

E-mail: jfernandoss@terra.com.br 